\title{
Moringa oleifera as an eco-friendly corrosion inhibitor for carbon steel in hydrochloric acid solution
}

\author{
A.S. Fouda, ${ }^{1 *(1)}$ A.M. Ahmed, ${ }^{2}$ S.M. El-Darier ${ }^{2}$ and I.M. Ibrahim ${ }^{2}$ \\ ${ }^{1}$ Chemistry Department, Faculty of Science, El-Mansoura University, Mansoura-35516, \\ Egypt \\ ${ }^{2}$ Chemistry Department, Faculty of Science, Alexandria University, Alexandria, Egypt \\ *E-mail: asfouda@hotmail.com
}

\begin{abstract}
The impact of aqueous extract of Moringa oleifera on the carbon steel dissolution in hydrochloric acid was investigated by chemical (mass loss) and electrochemical [potentiodynamic polarization (PP), electrochemical impedance spectroscopy (EIS), and electrochemical frequency modulation (EFM)] techniques. Atomic force microscope (AFM) and Fourier Transforms Infrared Spectra (FTIR) surface analysis techniques were used to illustrate the importance of this green Moringa oleifera extract in the corrosion inhibition process for carbon steel. The results demonstrated that the Moringa oleifera extract mitigates the corrosion of carbon steel in $1 \mathrm{M} \mathrm{HCl}$. From the mass loss test, it was found that with an increase in the concentration of Moringa oleifera extract up to $600 \mathrm{ppm}$, the inhibition efficacy increased to $91.7 \%$ at $25^{\circ} \mathrm{C}$, indicating that this extract is an excellent inhibitor for carbon steel in $\mathrm{HCl}$ medium. It was found that the inhibition efficacy decreased with raising temperature, indicating that the extract was adsorbed physically on carbon steel surface according to the Langmuir adsorption isotherm. The parameters of activation and adsorption processes are computed and discussed. Polarization data revealed that this extract behaved as a mixed kind inhibitor. Charge transfer resistance $\left(R_{\mathrm{ct}}\right)$ increased, while double layer capacitance $\left(C_{\mathrm{dl}}\right)$ decreased upon addition of the extract. A mechanism of the corrosion inhibition of carbon steel by Moringa oleifera extract was proposed and discussed.
\end{abstract}

Keywords: Moringa oleifera extract, corrosion inhibition, carbon steel, $\mathrm{HCl}$, Langmuir isotherm.

Received: September 24, 2020. Published: December 28, 2020

doi: $\underline{10.17675 / 2305-6894-2020-9-4-27}$

\section{Introduction}

Studies on carbon steel (CS) corrosion are of high importance. CS is utilized industrially for producing and designing materials, vessels, reaction tanks, and tubes for carrying the oil. It is effectively corroded in the presence of acids. The acids that interact with these materials are used in cleaning, pickling or descaling methods. Inhibitors used to decrease the dissolution process or corrosion rate are compounds that contain donating atoms such as $\mathrm{N}$, $\mathrm{O}$ and $\mathrm{S}$ atoms in their structures. The corrosion protection of metals and metal-based alloys 
by numerous plant extracts was studied [1-12]. The corrosion of CS by plant extracts has been investigated previously. Plant extracts proved to show good hindrance efficiencies [13]. In this paper, the limiting impact of Moringa oleifera extract on the CS corrosion in $1 \mathrm{M} \mathrm{HCl}$ was studied by utilizing mass loss (ML) and electrochemical techniques. The surface morphology was measured using an Atomic Force Microscope (AFM).

\section{Experimental}

The chemical composition of CS samples is: $0.039 \% \mathrm{P}, 0.04 \% \mathrm{~S}, 0.20 \% \mathrm{C}, 0.350 \% \mathrm{Mn}$, and Fe rest. The dimensions of the samples were: $2.0 \times 2.0 \times 0.2 \mathrm{~cm}$. They were polished to mirror finish with emery paper of various grades, washed with bidistilled water, and dried with filter papers.

\subsection{Preparation of plant extract (Moringa oleifera)}

Moringa oleifera was collected and dried in an oven at $70^{\circ} \mathrm{C}$. After this step, it was crushed, converted into powder, and $50 \mathrm{~g}$ of this powder was refluxed in $500 \mathrm{~mL}$ bidistilled water for $1 \mathrm{~h}$. The aqueous solution was filtered and concentrated to $100 \mathrm{~mL}$ [14]. This concentrated solution was utilized to prepare solutions with various concentrations by dilution.

\subsection{Mass loss $(M L)$ test}

The specimens were polished by emery paper, washed with bidistilled water, dried with tissue paper, and weighed. The samples were dipped in $\mathrm{HCl}$ in the presence and absence of various concentrations of the extract. The concentration of Moringa oleifera extract ranged from (100-600 ppm). The experiments were repeated three times every $30 \mathrm{~min}$ in order to check reproducibility. Subsequently, the specimens were weighed again. The $C R$ (corrosion rates) of the CS samples were calculated utilizing the following relationship [15]:

$$
C R=\Delta W / A t
$$

Where $\Delta W$ is the ML, $A$ is the sample surface area exposed to the solution in $\mathrm{cm}^{2}$, and $t$ is the immersion time in minutes. The inhibition efficiency $(\% I E)$ and the degree of surface coverage (degree of protection) $(\theta)$ were calculated using eq. (2):

$$
\% I E=\left[1-\left(\Delta W_{1} / \Delta W_{2}\right)\right] \cdot 100=\theta \cdot 100
$$

The data of MLs with and without Moringa oleifera extract are given by $\Delta W_{2}$ and $\Delta W_{1}$, correspondingly.

\subsection{Electrochemical techniques}

In this research, electrochemical measurements were done in a glass cell using a threeelectrode scheme. A platinum auxiliary electrode, a calomel reference electrode (SCE) coupled to a fine Luggin capillary, and a CS working electrode were employed. The working electrode was made as a square CS specimen with an exposed zone of $1 \mathrm{~cm}^{2}$. The terminal surface was treated in the same way as in the weight loss method. All the tests were 
performed at a temperature of $25^{\circ} \mathrm{C}$. The working electrode was placed in the used solution at the open circuit potential for 30 minutes, during which the stability condition was reached. The EFM electrochemical investigation was performed using a Gamry Potentiostat / Galvanostat / ZRA (PCI4-G750) device. Gamry includes DC105 DC Corrosion Program, EIS300 EIS program, the EFM140 for EFM program, and a computer for data collection. Echem Analyst version 5.5 was used to plot, calculate, and synthesize data.

\subsubsection{Potentiodynamic polarization (PP) measurements}

PP curves were recorded at a steady scan rate of $0.2 \mathrm{mV} \cdot \mathrm{s}^{-1}$ from $-0.7 \mathrm{~V}$ to $0.7 \mathrm{~V}$ (SCE). In this technique, the current density was determined and then used in the calculations. The experiments were repeated in triplicate. The \%IE value for Moringa oleifera extract was calculated as follows [16]:

$$
\% I E=\left[\left(i_{\text {corr }}-i_{\text {corr(inh })}\right) / i_{\text {corr }}\right] \cdot 100
$$

where $i_{\text {corr }}$ and $i_{\text {corr (inh) }}$ are the corrosion currents without and with Moringa oleifera extract, respectively.

\subsubsection{Electrochemical impedance spectroscopy (EIS) measurements}

In this technique, the study used the same cell as in the potentiodynamic technique. The experiments were performed at OCP using AC signals ranging from $100 \mathrm{kHz}$ to $0.1 \mathrm{~Hz}$ with a $10 \mathrm{mV}$ amplitude of peaks. The results of impedance measurements were compatible with the appropriate equivalent circuit by using the charge transfer resistance as a function of the protection quality by the following equation:

$$
\% I E=\left(1-R_{\mathrm{ct}} / R_{\mathrm{ct}}^{0}\right) \cdot 100
$$

Where $R_{\mathrm{ct}}$ and $R_{\mathrm{ct}}^{0}$ are the charge transfer resistances in the system in the presence and in the absence of Moringa oleifera extract, respectively.

\subsubsection{Electrochemical frequency modulation (EFM) measurements}

The EFM experiment is performed by applying a $10 \mathrm{mV}$ signal through two sinus waves ranging from 2 to $5 \mathrm{~Hz}$ [17]. This technology is fast and nondestructive. The corrosion current density $\left(i_{\text {corr }}\right)$ was determined from the higher peaks.

\subsection{Surface examinations}

\subsubsection{AFM analysis}

By using the atomic force spectroscopy technique (AFM), the morphological properties of the CS metal surface were studied. This study was performed in $1 \mathrm{M}$ hydrochloric acid in the presence of the highest concentration of Moringa oleifera extract (600 ppm) and in the 
absence of a corrosion inhibitor. AFM was carried out in contact mode using a silicon nitride probe (MLCT model; Bruker).

\subsubsection{Fourier Transforms Infrared Spectra (FTIR) investigation}

For the determination of the functional groups present in Moringa oleifera extract, CS samples were dipped in the corrosive solution with and without $600 \mathrm{ppm}$ Moringa oleifera extract for 3 hours, then removed, dried, and kept in a desiccator until the investigation.

\section{Results and discussion}

\subsection{ML test}

The ML values of $\mathrm{CS}$ in $\mathrm{HCl}$ solution with and without various concentrations of the extract after various dipping times $(30-150 \mathrm{~min})$ at $25^{\circ} \mathrm{C}$ are given in Figure 1 . The curves in Figure 1 in the presence of the extract lie the curve in the absence of an inhibitor. These curves are the lines that indicate the absence of solid products (oxide films) on the CS surface. The data on $C R\left(\mathrm{mg} \cdot \mathrm{cm}^{-2} \cdot \mathrm{min}^{-1}\right), \theta$, and $\% I E$ of CS in hydrochloric acid with different concentrations of Moringa oleifera extract are listed in Table 1.\%IE improved with raising the concentration of Moringa oleifera and temperature. The inhibition results from the adsorption of Moringa oleifera extract on the CS and the formation of a layer from adsorbed molecules on the surface of CS that separates the CS from the acidic environment and blocks the areas of corrosion [18-20].

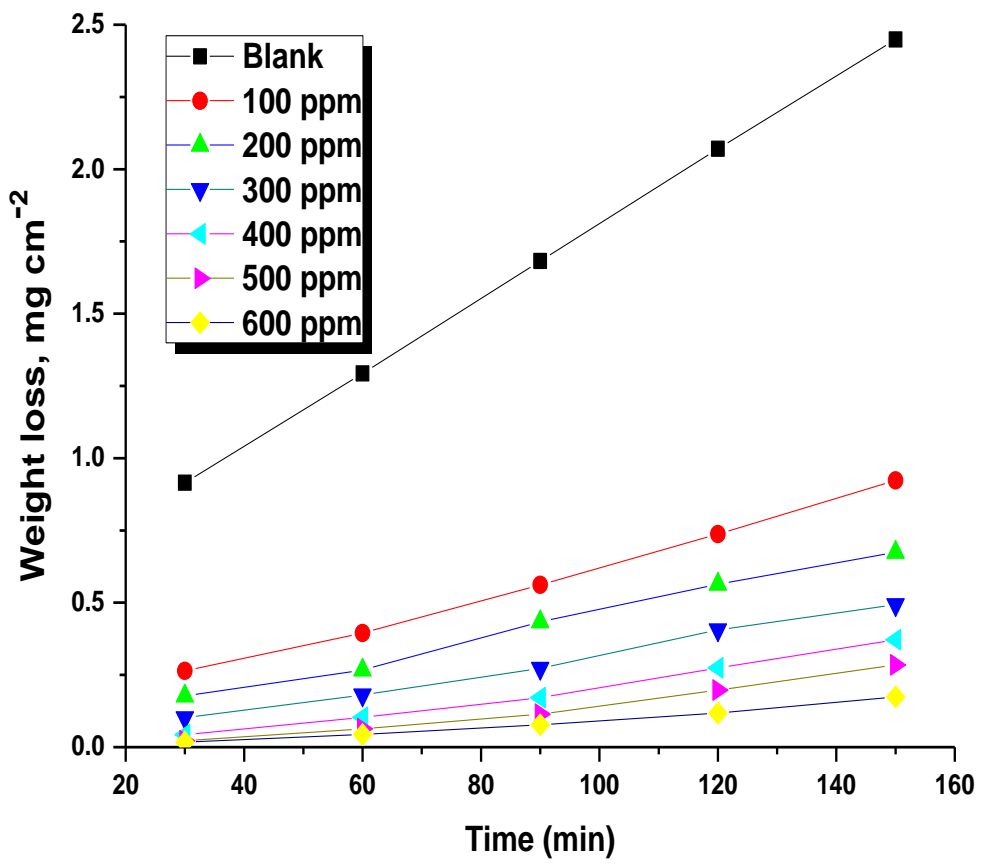

Figure 1. $\mathrm{ML}$ of $\mathrm{CS}$ in $1 \mathrm{M} \mathrm{HCl}$ solution in the Moringa oleifera extract at different concentrations. 
Table 1. Influence of various concentrations of Moringa oleifera extract on the $C R$ and \%IE of CS in $\mathrm{HCl}$ at various temperatures.

\begin{tabular}{cccccccccccc}
\hline \multirow{2}{*}{$\begin{array}{c}\text { Conc. } \\
\text { (ppm) }\end{array}$} & \multicolumn{2}{c}{$\mathbf{2 5}^{\circ} \mathbf{C}$} & \multicolumn{2}{c}{$\mathbf{3 0}^{\circ} \mathbf{C}$} & \multicolumn{2}{c}{$\mathbf{3 5}^{\circ} \mathbf{C}$} & \multicolumn{2}{c}{$\mathbf{4 0}^{\circ} \mathbf{C}$} & \multicolumn{2}{c}{$\mathbf{4 5}^{\circ} \mathbf{C}$} \\
\hline & $\boldsymbol{C R}$ & \%IE & $\boldsymbol{C R}$ & \%IE & $\boldsymbol{C R}$ & \% IE & $\boldsymbol{C R}$ & \% IE & $\boldsymbol{C R}$ & \% IE \\
\hline Blank & 0.116 & - & 0.0141 & - & 0.192 & - & 0.419 & - & 0.513 & - \\
\hline 100 & 0.0266 & 77.1 & 0.0348 & 75.3 & 0.0509 & 73.5 & 0.1194 & 71.5 & 0.1575 & 69.3 \\
200 & 0.0197 & 83.0 & 0.0303 & 78.5 & 0.0444 & 76.9 & 0.1039 & 75.2 & 0.1380 & 73.1 \\
300 & 0.0165 & 85.8 & 0.0261 & 81.5 & 0.0394 & 79.5 & 0.0901 & 78.5 & 0.1195 & 76.7 \\
400 & 0.0130 & 88.8 & 0.0219 & 84.5 & 0.0359 & 81.3 & 0.0758 & 81.9 & 0.1011 & 80.3 \\
500 & 0.0104 & 91.0 & 0.0212 & 85.0 & 0.0271 & 85.9 & 0.0645 & 84.6 & 0.0811 & 84.2 \\
600 & 0.0096 & 91.7 & 0.0147 & 89.6 & 0.0219 & 88.6 & 0.0528 & 87.4 & 0.0713 & 86.1 \\
\hline
\end{tabular}

\subsection{Adsorption isotherms}

Moringa oleifera extract was adsorbed on the CS surface and the data of $(\theta)$ for various concentrations of Moringa oleifera extract in $1 \mathrm{M}$ hydrochloric acid were determined from ML data by using equation (1). The $\theta$ values increased with an increase in the Moringa oleifera extract concentration. By matching these data to various adsorption isotherms, the Langmuir adsorption isotherm was recognized to be the best explanation of the extract adsorption behavior on the surface of CS. The Langmuir equation is [21]:

$$
C / \theta=1 / K_{\text {ads }}+C
$$

A plot of $C$ vs. $C / \theta$ for Moringa oleifera extract at various temperatures is shown in Figure 2 . The intercept equals $\left(1 / K_{\text {ads }}\right)$, the slope reaches unity, and the relationship between the adsorption binding constant and $\Delta G_{\text {ads }}^{0}$ is given by:

$$
\Delta G_{\mathrm{ads}}^{0}=-R T \ln \left(55.5 K_{\mathrm{ads}}\right)
$$

The $\Delta G_{\text {ads }}^{0}$ data at all temperatures are documented in Table 3. The $\Delta H_{\text {ads }}^{0}$ values were determined by the Van't Hoff equation [22]:

$$
\log K_{\text {ads }}=\left(\frac{-\Delta H_{\mathrm{ads}}^{0}}{2.303 R T}\right)+\text { constant }
$$

Plotting $\left(\log K_{\text {ads }}\right) v s .(1 / T)$ gives a straight line as displayed in Figure 3 and the slope is $\left(-\Delta H_{\text {ads }}^{0} / 2.303 R\right)$. From this slope, the $\Delta H_{\text {ads }}^{0}$ data was calculated and is listed in Table 3. Then, the following equation is applied:

$$
\Delta G_{\mathrm{ads}}^{0}=\Delta H_{\mathrm{ads}}^{0}-T \Delta S_{\mathrm{ads}}^{0}
$$




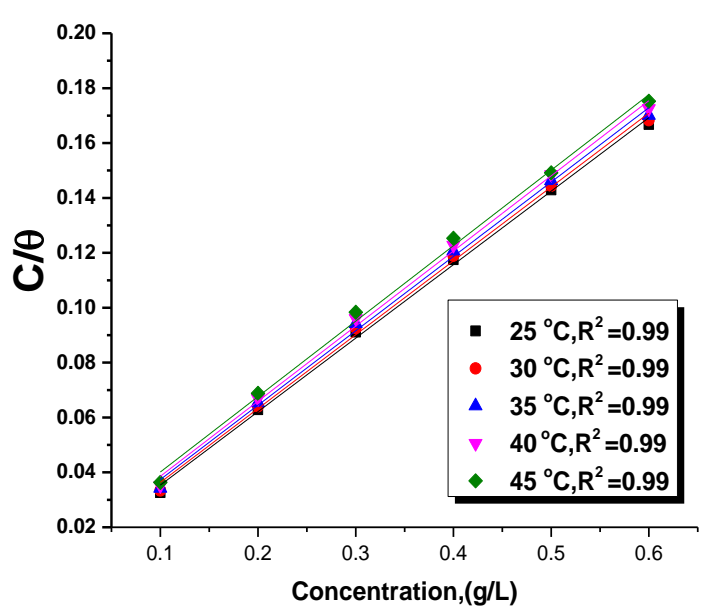

Figure 2. Langmuir plots of Moringa oleifera on CS surface in $1 \mathrm{M} \mathrm{HCl}$ at various temperatures.

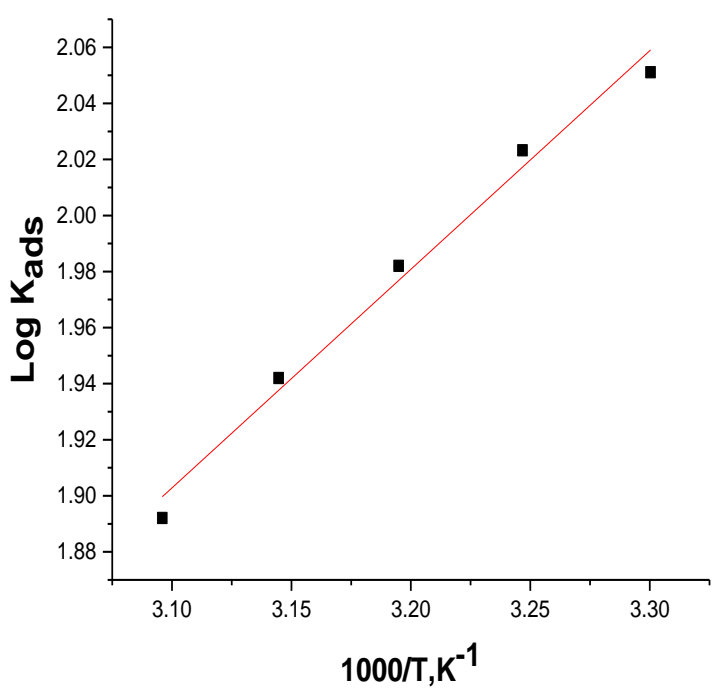

Figure 3. $\left(\log K_{\mathrm{ads}}\right) v s .(1 / \mathrm{T})$ plot for the dissolution of $\mathrm{CS}$ in $1 \mathrm{M} \mathrm{HCl}$ with and without Moringa oleifera extract at various temperatures.

Table 2 shows the adsorption parameters of the Moringa oleifera extract. The data shown in the table confirm the spontaneous adsorption of Moringa oleifera extract on the CS surface through the negative $\Delta G_{\text {ads }}^{0}$ values obtained. It is negative (spontaneous) and decreases with higher temperature indicating that the adsorbed layer is more stable at low temperatures. The $\Delta G_{\text {ads }}^{0}$ values smaller than $-20 \mathrm{~kJ} / \mathrm{mol}$ are indicative of physical adsorption. Hence, these results show that physical adsorption occurs. When the value of enthalpy is negative, this means that the adsorption of Moringa oleifera extract molecules is exothermic. An exothermic process can refer to physical or chemical adsorption, but the value determines the kind of adsorption. The $\Delta H_{\text {ads }}^{0}$ value that is less than $40 \mathrm{~kJ} / \mathrm{mol}$ refers 
to a physisorption process, while the $\Delta S_{\text {ads }}^{0}$ values are positive due to an increase in disorder resulting from the water molecules adsorbing on the CS surface [23].

Table 2. Parameters of Langmuir adsorption of Moringa oleifera extract on the CS surface at various temperatures.

\begin{tabular}{ccccc}
\hline Temp., ${ }^{\circ} \mathbf{C}$ & $\boldsymbol{K}_{\text {ads }}, \mathbf{M}^{\mathbf{- 1}}$ & $-\Delta \boldsymbol{G}_{\text {ads }}^{\mathbf{0}}, \mathbf{k J} \cdot \mathbf{m o l}^{\mathbf{- 1}}$ & $-\Delta \boldsymbol{H}_{\text {ads }}^{\mathbf{0}}, \mathbf{k J} \cdot \mathbf{m o l} \mathbf{- 1}^{\mathbf{1}}$ & $\boldsymbol{\Delta} \boldsymbol{S}_{\text {ads }}^{\mathbf{0}}, \mathbf{J} \cdot \mathbf{m o l} \mathbf{- 1}^{\mathbf{1}} \mathbf{K}^{\mathbf{1}}$ \\
\hline 25 & 120 & 22.3 & & 69.1 \\
30 & 112 & 21.1 & & 68.2 \\
35 & 100 & 20.2 & 24.3 & 66.0 \\
40 & 92 & 19.3 & & 64.8 \\
45 & 80 & 18.4 & 63.0 \\
\hline
\end{tabular}

\subsection{Thermodynamic parameters}

In this examination, the effect of temperature on the corrosion of CS samples used in the investigation and dipped in $1 \mathrm{M}$ hydrochloric acid was studied with and without various concentrations of Moringa oleifera extract. It was found that the $C R$ increased with increasing temperature. Table 3 shows the effect of temperature on the activation parameters in the presence and absence of Moringa oleifera extract in the temperature range used. The table shows the CS activation energy $\left(E_{\mathrm{a}}^{*}\right)$ calculated from the slope of the graph using the Arrhenius formula:

$$
\log C R=\log A-E_{\mathrm{a}}^{*} / 2.303 R T
$$

Where $A$ is the Arrhenius exponential factor. Arrhenius diagrams are illustrated in Figure 4 $[\log (C R) v s .1 / T]$, in which the activation energy is derived from the slopes of the straight lines $\left[-E_{\mathrm{a}}^{*} / 2.303 R\right]$. By using the transitional state equation, the changes in entropy and enthalpy were calculated [24-27].

$$
\log (C R / T)=\left[\log (R / N h)+\Delta S_{\mathrm{a}}^{*} / 2.303 R\right]-\Delta H_{\mathrm{a}}^{*} / 2.303 R T
$$

Where $h$ is the Planck constant. Figure 5 shows straight lines resulting from a plot of $\log (C R / T)$ vs. 1000/T, where this figure shows the transitional state of the Moringa oleifera extract. The slopes obtained from the plot were used to calculate enthalpy $\left(\Delta H_{\mathrm{a}}^{*} / 2.303 R\right)$ and the activation entropy of the plot was calculated from the intercepts of the lines $\left[\log (R / N h)+\Delta S_{\mathrm{a}}^{*} / 2.303 R\right]$. Analysis of the results shown in Table 3 indicates that the activation energy increases with an increase in the concentration of Moringa oleifera extract. This increase is due to the nature of adsorption of Moringa oleifera extract on the CS surface that corresponds to the physical adsorption of the components of extract [28]. The results in Table 3 also show that the entropy values are negative in the presence of Moringa oleifera 
extract. These negative values show that the activated complex in the rate-determining step prefers the association step to the dissociation step [29].

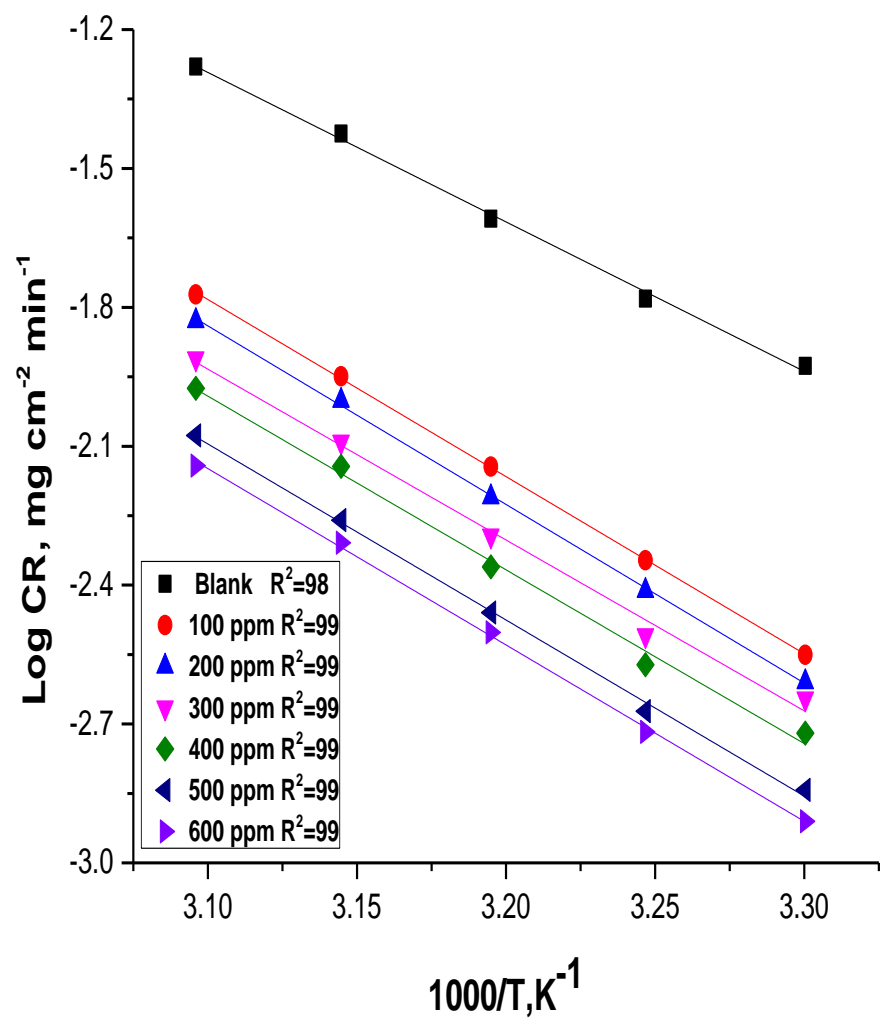

Figure 4. $\log C R v s .1 / T$ curves for various concentration of Moringa oleifera extract.

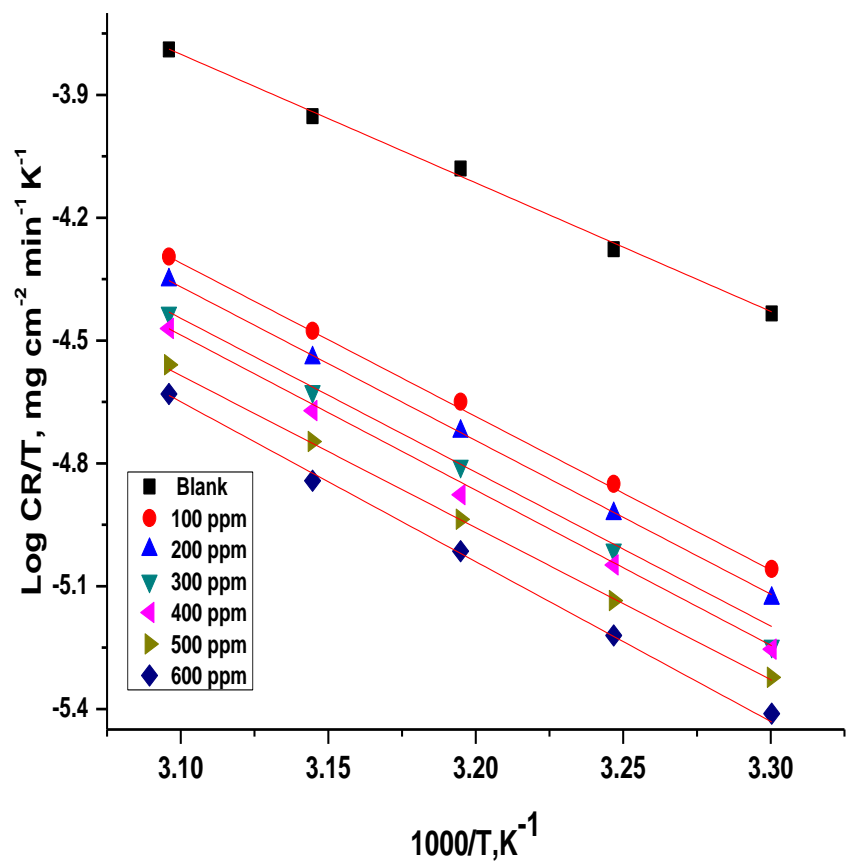

Figure 5. $\log (C R / T)$ vs. 1/T diagram for various concentrations of Moringa oleifera extract. 
Table 3. Thermodynamic parameters for dissolution of CS at various concentrations of Moringa oleifera extract in $1 \mathrm{M} \mathrm{HCl}$ solution.

\begin{tabular}{cccc}
\hline Conc., $\mathbf{p p m}$ & $\boldsymbol{E}_{\mathrm{a}}^{*}, \mathbf{k J} \mathbf{~ m o l}^{\mathbf{1}}$ & $\Delta \boldsymbol{H}^{*}, \mathbf{k J} \cdot \mathbf{m o l}^{\mathbf{1}}$ & $-\Delta \boldsymbol{S}^{*}, \mathbf{J} \cdot \mathbf{m o l}^{\mathbf{- 1} \cdot \mathbf{K}^{\mathbf{1}}}$ \\
\hline Blank & 64.9 & 62.2 & 88.3 \\
\hline 100 & 75.9 & 73.2 & 83.3 \\
200 & 76.5 & 73.8 & 61 \\
300 & 76.6 & 73.9 & 60.5 \\
400 & 78.3 & 75.6 & 58.9 \\
500 & 79.6 & 76.9 & 58 \\
600 & 81.4 & 78.8 & 57.2 \\
\hline
\end{tabular}

\subsection{PP tests}

Figure 6 displays the PP diagrams for CS with various concentrations of Moringa oleifera extract at $25^{\circ} \mathrm{C}$. From Figure 6, both cathodic (hydrogen discharge) and anodic reactions (carbon steel dissolution) were inhibited by adding various concentrations of Moringa oleifera extract. The electrochemical parameters, $E_{\text {corr }}, C R, \theta, \% I E$, and $i_{\text {corr }}$ were measured and are given in Table 4 . The data showed that addition of the extract decreased the $i_{\text {corr }}$ values, while it did not change the $E_{\text {corr }}$ values [30]. Thus, the Moringa oleifera extract performance is as a mixed kind inhibitor.

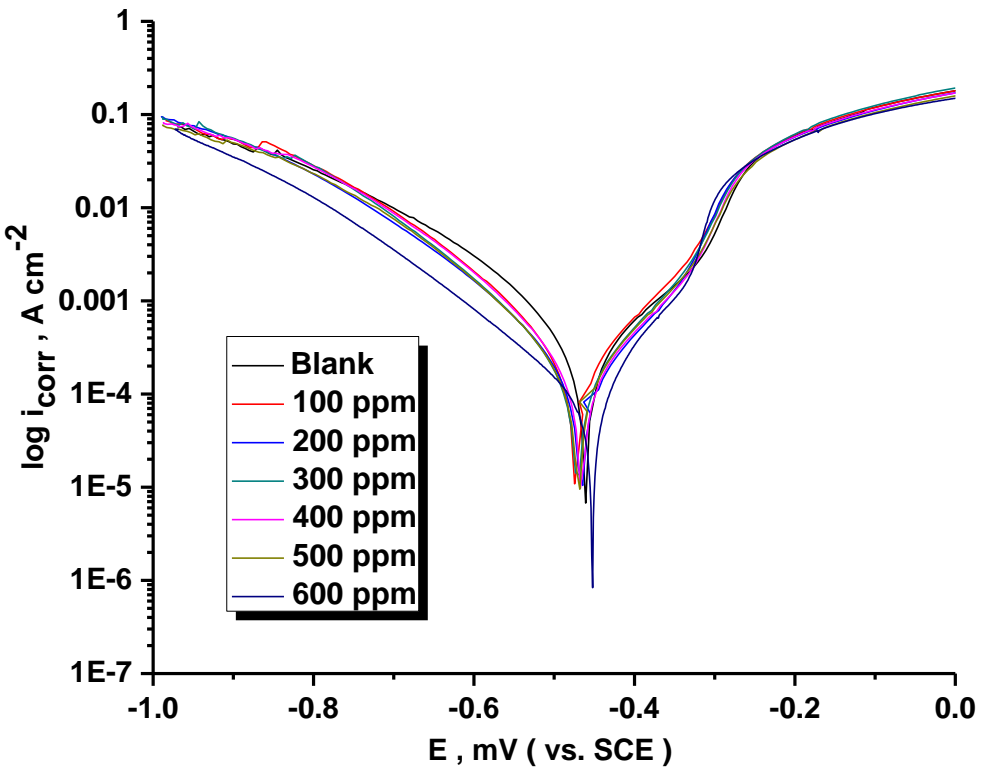

Figure 5. $\mathrm{PP}$ diagram for $\mathrm{CS}$ in $1 \mathrm{M} \mathrm{HCl}$ with various concentrations of Moringa oleifera extract at $25^{\circ} \mathrm{C}$. 
Table 4. Electrochemical parameters: $i_{\text {corr }}, E_{\text {corr, }} \theta$ and $I E \%$ of $\mathrm{CS}$ in $1 \mathrm{M} \mathrm{HCl}$ with various concentrations of Moringa oleifera extract.

\begin{tabular}{cccccc}
\hline $\begin{array}{c}\text { Conc., } \\
\mathbf{p p m}\end{array}$ & $\begin{array}{c}\text { icorr, } \\
\boldsymbol{\mu A} \cdot \mathbf{c m}^{-2}\end{array}$ & $\begin{array}{c}-\boldsymbol{E}_{\text {corr, }} \\
\mathbf{m V} \boldsymbol{v s .} \mathbf{S C E}\end{array}$ & $\begin{array}{c}\boldsymbol{C R}, \\
\mathbf{m p y}\end{array}$ & $\boldsymbol{\theta}$ & $\boldsymbol{\%} \boldsymbol{I E}$ \\
\hline Blank & 2530 & 461 & 138 & - & - \\
100 & 1016 & 462 & 11.9 & 0.598 & 59.8 \\
200 & 808 & 466 & 10.5 & 0.681 & 68.1 \\
300 & 693 & 471 & 5.6 & 0.726 & 72.6 \\
400 & 568 & 476 & 4.9 & 0.775 & 77.5 \\
500 & 448 & 479 & 4.4 & 0.823 & 82.3 \\
600 & 372 & 483 & 3.8 & 0.853 & 85.3 \\
\hline
\end{tabular}

\subsection{EIS tests}

Figures $(7,8)$ display the CS Nyquist and Bode plots recorded at OCP with and without various concentrations of Moringa oleifera extract at $25^{\circ} \mathrm{C}$, respectively. The EIS spectra show that the diameter increases with an increase in the dose of Moringa oleifera extract. The interface capacitance $C_{\mathrm{dl}}$ can be estimated from CPE parameters $Y_{0}$ and $n$, as defined in eq. 11:

$$
C_{\mathrm{dl}}=Y_{0} \cdot\left(\omega_{\max }\right)^{\mathrm{n}-1}
$$

Where, $Y_{0}$ is the CPE magnitude and $n$ is the CPE variable: $-1<n<1$.

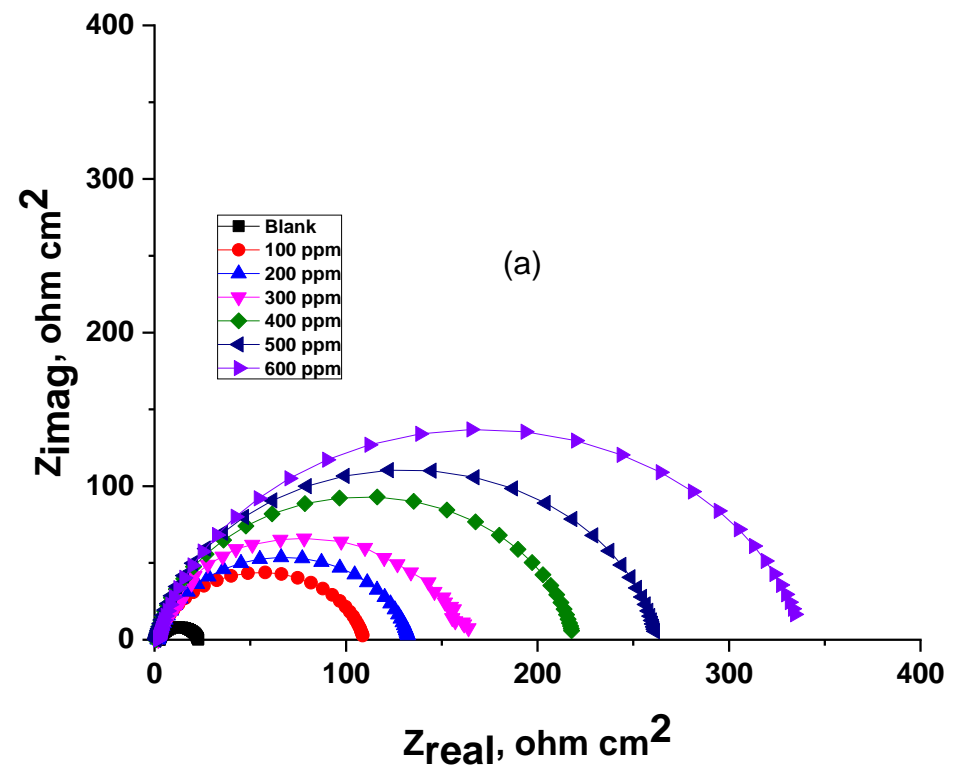

Figure 7. Nyquist diagrams for dissolution of $\mathrm{CS}$ with and without various concentrations of Moringa oleifera extract at $25^{\circ} \mathrm{C}$. 


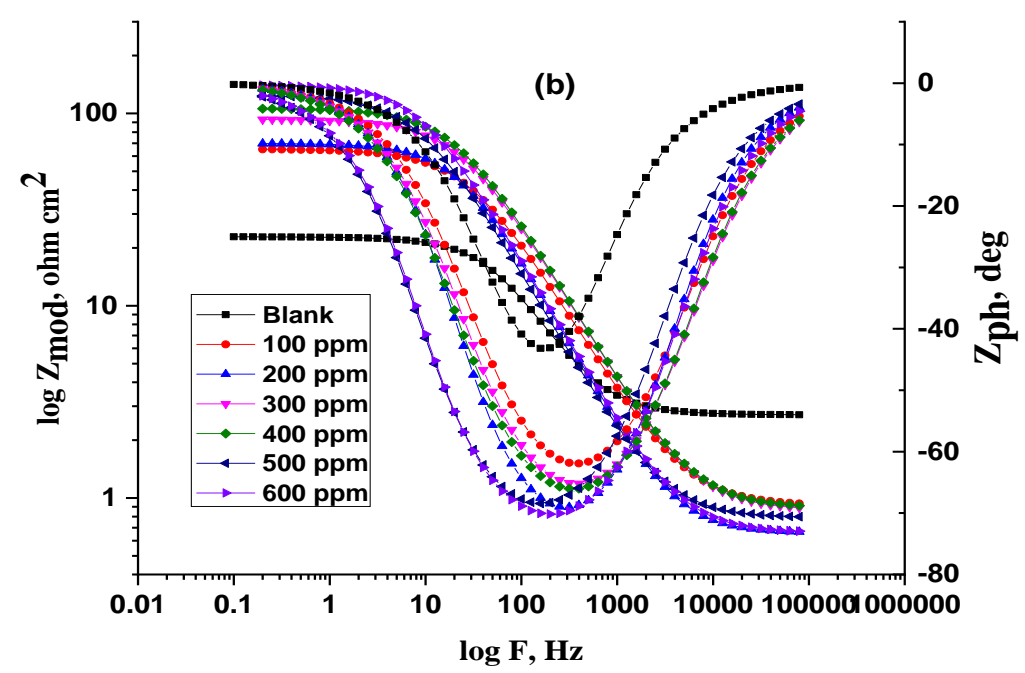

Figure 8. Bode diagrams for dissolution of CS with and without various concentrations of Moringa oleifera extract at $25^{\circ} \mathrm{C}$.

The curves obtained are very similar for all samples with and without various concentrations of Moringa oleifera extract indicating that no changes in the corrosion mechanism occur [31]. Table 5 demonstrates that the impedance data of $R_{\mathrm{ct}}$ increase with raising the dose of the Moringa oleifera extract, showing that \%IE increases. This might be because of the rise of the thickness of the adsorbed layer with an increase in the Moringa oleifera extract concentration. Table 5 lists the values of $R_{\mathrm{s}}$ and $R_{\mathrm{ct}}$ parameters from EIS fitting and the derived parameters $C_{\mathrm{dl}}$ and $\% I E$.

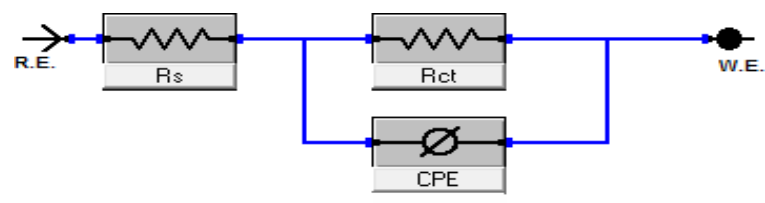

Figure 9. Electrical circuit utilized to fit the EIS data.

Table 5. EIS data for CS dissolution without and with various concentrations of Moringa oleifera extract at $25^{\circ} \mathrm{C}$.

\begin{tabular}{ccccc}
\hline Conc., $(\mathbf{p p m})$ & $\boldsymbol{R}_{\mathrm{ct}}, \boldsymbol{\Omega} \cdot \mathbf{c m}^{\mathbf{2}}$ & $\boldsymbol{C}_{\mathrm{dll}}, \boldsymbol{\mu \mathbf { F } \cdot \mathbf { c m } ^ { - 2 }}$ & $\boldsymbol{\theta}$ & $\boldsymbol{\%} \boldsymbol{I E}$ \\
\hline 0 & 25 & 385 & - & - \\
100 & 132 & 141 & 0.811 & 81.1 \\
200 & 145 & 106 & 0.828 & 82.8 \\
300 & 164 & 98 & 0.848 & 84.8 \\
400 & 210 & 91 & 0.881 & 88.1 \\
500 & 270 & 79 & 0.907 & 90.7 \\
600 & 341 & 73 & 0.927 & 92.7 \\
\hline
\end{tabular}




\subsection{EFM tests}

The data derived from EFM for CS in $1 \mathrm{M} \mathrm{HCl}$ with various concentrations of Moringa oleifera extract at $25^{\circ} \mathrm{C}$ are shown in Table 6 . The data show that the corrosion rate decreases with an increase in the concentration of Moringa oleifera extract, while the \%IE increases. The $i_{\text {corr }}$ data can be obtained directly from EFM measurements and the Tafel constants determined independently [32]. The \%IE can be calculated as shown in Eq. 4. The intermodulation spectra obtained from EFM with and without various concentrations of Moringa oleifera extract are displayed in Figure 10.
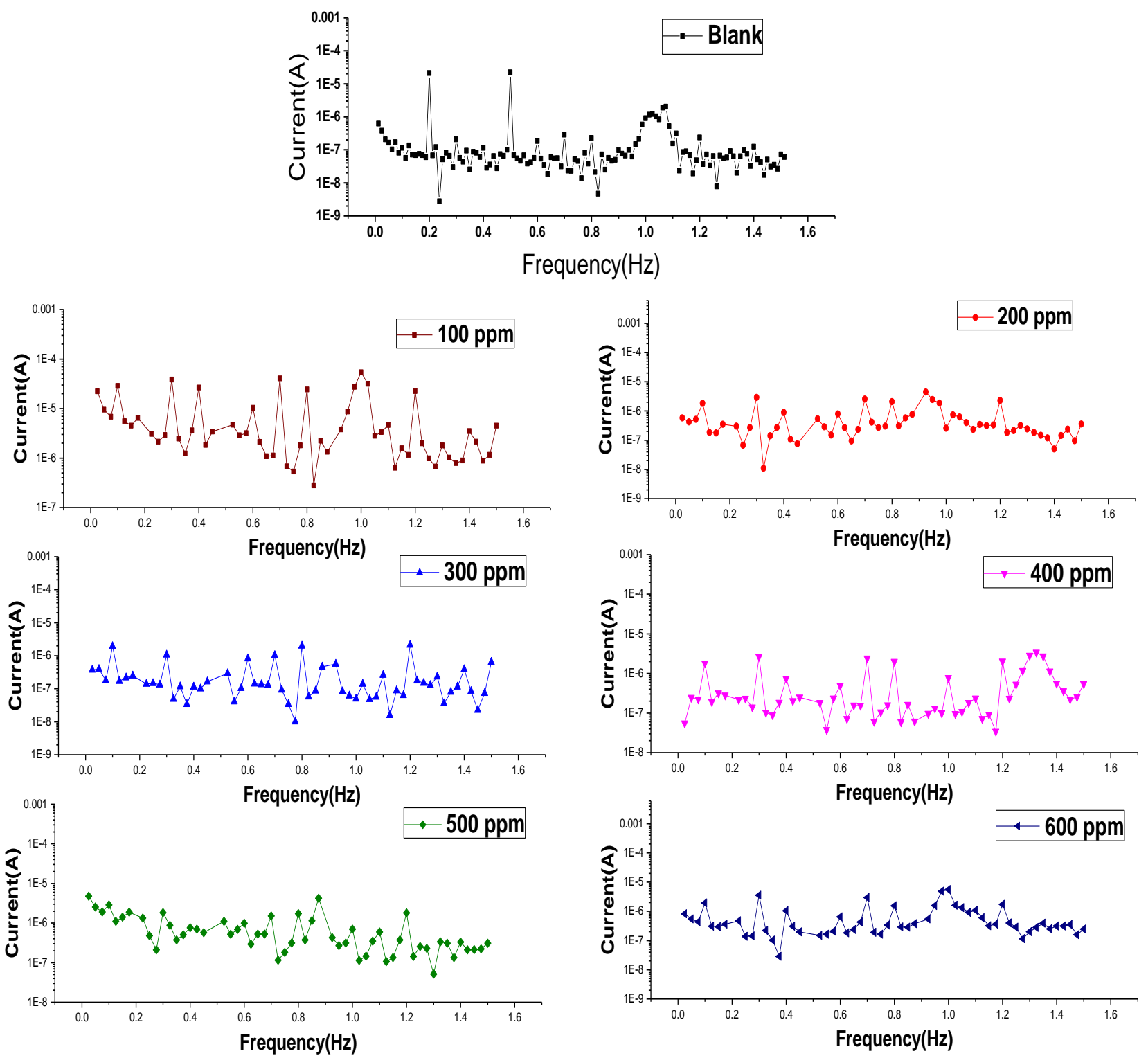

Figure 10. Intermodulation spectrum of $\mathrm{CS}$ in $1 \mathrm{M} \mathrm{HCl}$ with and without various concentrations of Moringa oleifera extract. 
Table 6. EFM for CS with and without various concentrations of Moringa oleifera extract at $25^{\circ} \mathrm{C}$.

\begin{tabular}{ccccc}
\hline Conc., $(\mathbf{p p m})$ & $\boldsymbol{i}_{\text {corr, }} \boldsymbol{\mu} \mathbf{\mu} \cdot \mathbf{c m}^{-2}$ & $\boldsymbol{C R}, \mathbf{m p y}$ & $\boldsymbol{\theta}$ & $\boldsymbol{\%} \boldsymbol{I E}$ \\
\hline 0 & 4763 & 118 & - & - \\
100 & 943 & 60 & 0.802 & 80.2 \\
200 & 876 & 44 & 0.816 & 81.6 \\
300 & 738 & 36 & 0.845 & 84.5 \\
400 & 600 & 33 & 0.874 & 87.4 \\
500 & 476 & 12 & 0.902 & 90.2 \\
600 & 391 & 11 & 0.918 & 91.8 \\
\hline
\end{tabular}

\subsection{Surface morphology}

\subsubsection{AFM analysis}

The CS surface morphology was analyzed by using AFM experiments after exposure for $24 \mathrm{~h}$ to $1 \mathrm{M} \mathrm{HCl}$ in the presence and absence of $600 \mathrm{ppm}$ of Moringa oleifera extract. Figure 11(a) shows the clear CS surface, Figure 11(b) gives the surface of the metal that was damaged by $\mathrm{HCl}$, and Figure 11(c) displays the surface of the metal in the presence of $600 \mathrm{ppm}$ of Moringa oleifera extract that was not affected by corrosion.

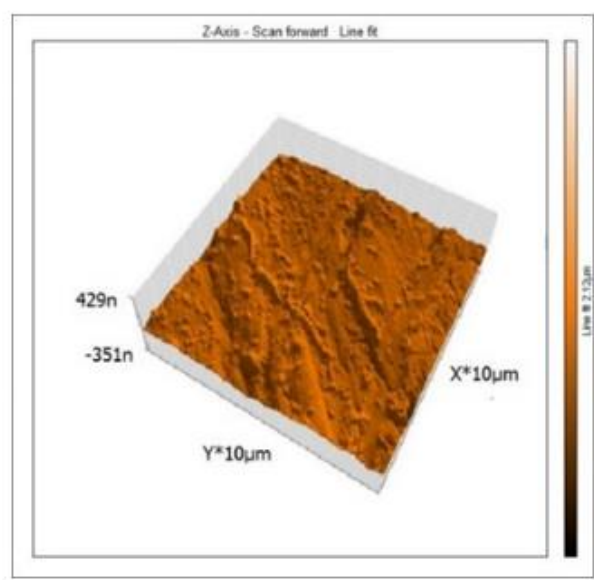

$3 \mathrm{D}$

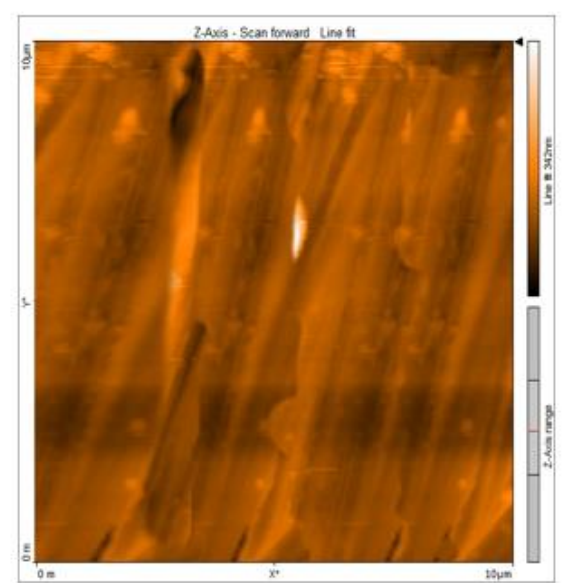

$2 \mathrm{D}$

Figure 11(a). (3D), (2D) AFM micrograph of CS before exposure to the acid. 


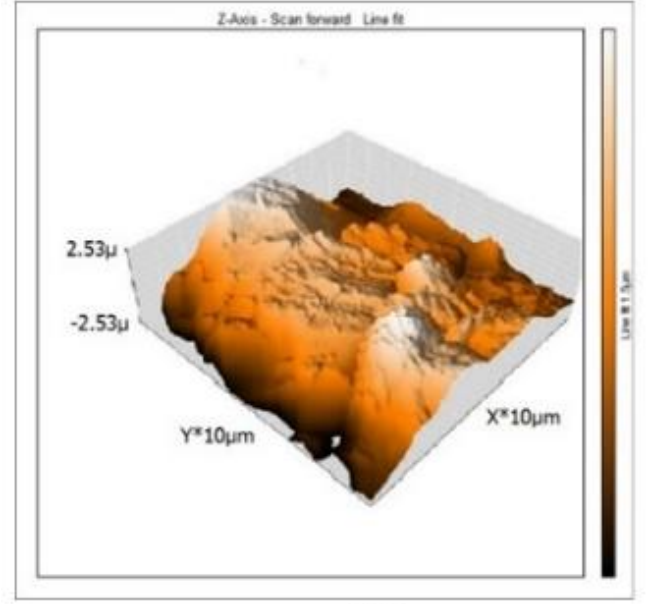

$3 \mathrm{D}$

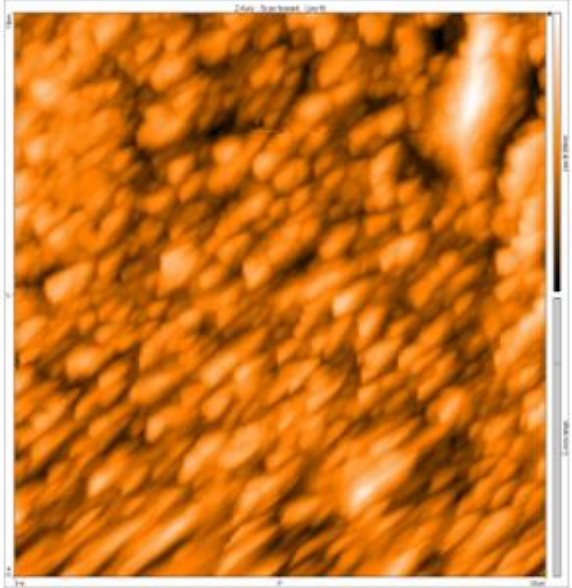

$2 \mathrm{D}$

Figure 11(b). (3D), (2D) corroded CS surface after exposure to the corrosive environment (blank solution alone).

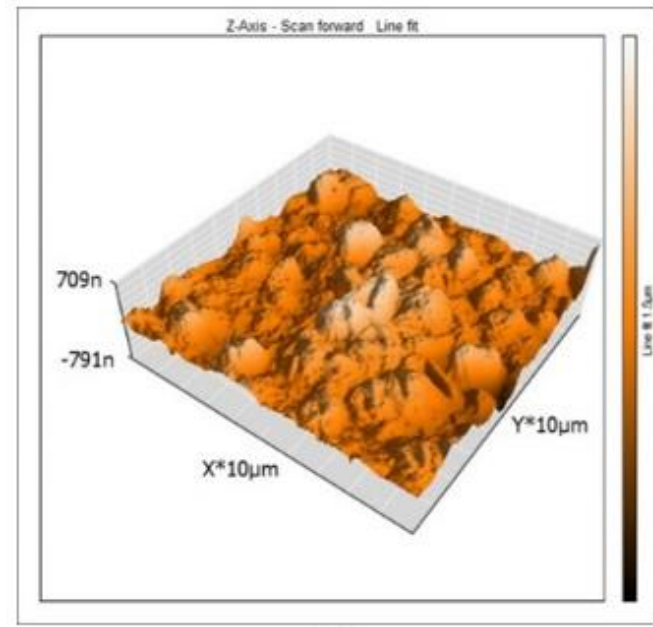

$3 \mathrm{D}$

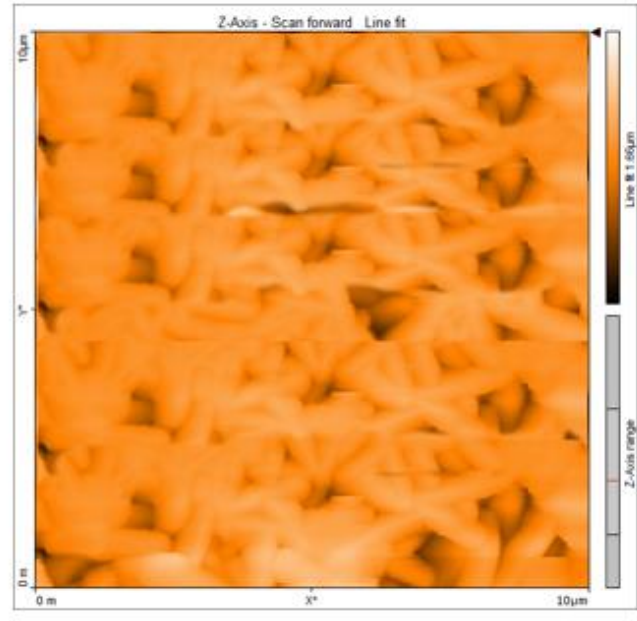

2D

Figure 11(c). (3D), (2D) of the inhibited CS surface after exposure to the acid solution with $600 \mathrm{ppm}$ of Moringa oleifera extract for 24 hours at $25^{\circ} \mathrm{C}$.

\subsubsection{Fourier Transform Infrared Spectra (FTIR) studies}

FTIR is a powerful investigative tool to expose the functional groups in a molecule. The FTIR spectra of Moringa oleifera extract with and without the metal surface are shown in Figure 12 to exhibit a broad band at $3330 \mathrm{~cm}^{-1}$ that revealed the vibration of the $\mathrm{N}-\mathrm{H}$ bond. The band at $1635 \mathrm{~cm}^{-1}$ revealed the vibration of $\mathrm{C}=\mathrm{O}$, that at $1051 \mathrm{~cm}^{-1}$ revealed the stretching $v(\mathrm{C}-\mathrm{O})$, and the bands below $1000 \mathrm{~cm}^{-1}$ correspond to aliphatic and aromatic $(\mathrm{C}-\mathrm{H})$ groups [33]. It is observed that there are movement in the frequencies, namely, the $\mathrm{N}-\mathrm{H}$ band shifted from $3330 \mathrm{~cm}^{-1}$ to $3335 \mathrm{~cm}^{-1}$, and the band corresponding to the stretching vibration of $\mathrm{C}=\mathrm{O}$ shifted from $1635 \mathrm{~cm}^{-1}$ to $1649 \mathrm{~cm}^{-1}$. 


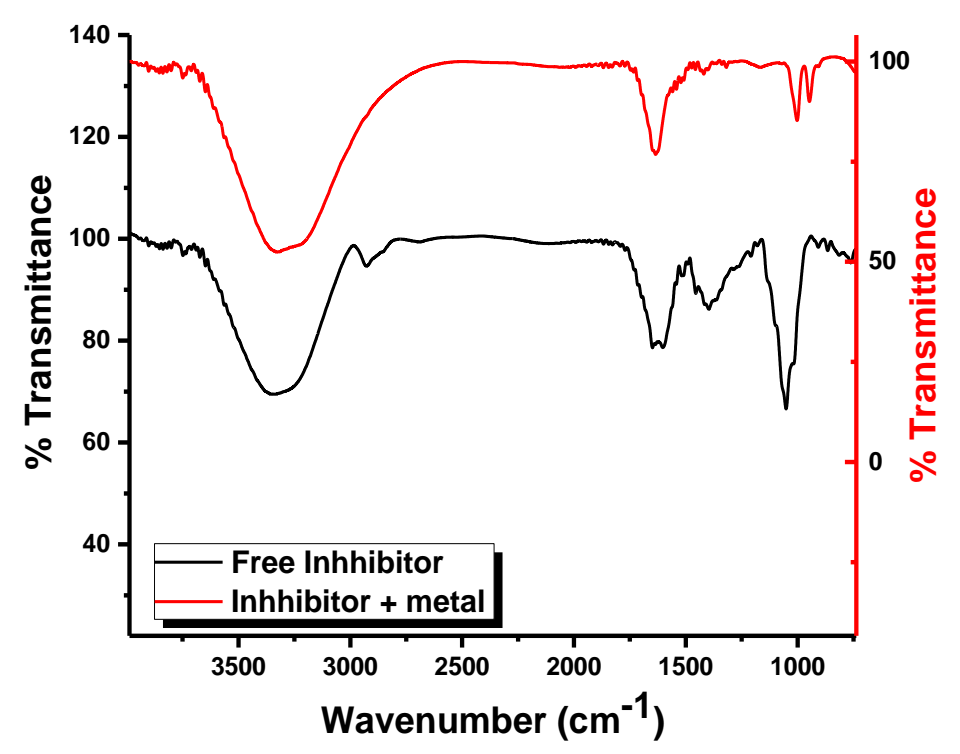

Figure 12. FTIR spectrum of Moringa oleifera extract before and after adsorption on the CS surface.

\subsection{Inhibition mechanism}

Moringa oleifera extract includes anthraquinones, flavonoids, polyphenols, lipids, and sterols [34]. The adsorption on the CS surface (via chemisorption) involves the removal of water molecules from the CS surface and the interaction of electrons between the iron and oxygen or Moringa oleifera adsorbed by donor-acceptor bonds between vacant $d$ orbitals of iron and $\pi$-electrons of aromatic rings. In the acid medium, the steel surface bears a positive charge, so it is hard for protonated molecules to adsorb on the CS surface due to electrostatic repulsion. The chloride ions adsorbed on CS surface create an excess negative charge toward the solution and adsorption for the cations [3]. Owing to the lone pair of electrons, the $\mathrm{O}$ and $\mathrm{N}$ atoms in Moringa oleifera molecules or protonated molecules may be bound to the newly formed positive ions of iron on CS surface to form complexes with the CS inhibitor (Moringa oleifera extract). These complexes are adsorbed on the CS through van der Waals forces to form a protective cover preventing CS from dissolution.

\section{Conclusion}

The inhibiting effect of Moringa oleifera extract on the CS corrosion in $\mathrm{HCl}$ was studied. The mitigation increases with an increase in the Moringa oleifera extract concentration. Moringa oleifera is adsorbed chemically and physically on the CS obeying the Langmuir isotherm. The results obtained from potentiodynamic polarization measurements indicate that this extract acts as a mixed type inhibitor. The results obtained from ML and electrochemical tests are in excellent agreement. 


\section{References}

1. A.M. Shah, A.A. Rahim, S.A. Hamid and S. Yahya, Green Inhibitors for Copper Corrosion by Mangrove Tannin, Int. J. Electrochem. Sci., 2013, 8, 2140-2153.

2. M.A. Quraishi, A. Singh, V.K. Singh, D.K. Yadav and A.K. Singh, Green approach to corrosion inhibition of mild steel in hydrochloric acid and sulphuric acid solutions by the extract of Murraya koenigii leaves, Mater. Chem. Phys., 2010, 122, no. 1, 114-122. doi: 10.1016/j.matchemphys.2010.02.066

3. A.S. Fouda, S.A. Abd El-Maksoud, A. El-Hossiany and A. Ibrahim, Corrosion Protection of Stainless Steel 201 in Acidic Media using Novel Hydrazine Derivatives as Corrosion Inhibitors, Int. J. Electrochem. Sci., 2019, 14, 2187-2207.

4. A.S. Fouda, S. Rashwan, A. El-Hossiany and F.E. El-Morsy, Corrosion Inhibition of Zinc in Hydrochloric Acid Solution using some organic compounds as Eco-friendly Inhibitors, J. Chem., Biol. Phys. Sci., 2018, 19, no. 1, 001.

5. A.S. Fouda, S.A. Abd El-Maksoud, A.A.M. Belal, A. El-Hossiany and A. Ibrahium, Effectiveness of Some Organic Compounds as Corrosion Inhibitors for Stainless Steel 201 in 1M HCl: Experimental and Theoretical Studies, Int. J. Electrochem. Sci., 2018, 13, 9826-9846. doi: $10.20964 / 2018.10 .36$

6. A.S. Fouda, M.A. Abd El-Ghaffar, M.H. Sherif, A. Taher El-Habab and A. ElHossiany, Novel Anionic 4-Tert-Octyl Phenol Ethoxylate Phosphate Surfactant as Corrosion Inhibitor for C-steel in Acidic Media, Prot. Met. Phys. Chem. Surf., 2020, 56, no. 1, 189-201. doi: $10.1134 /$ S2070205120010086

7. A.S. Fouda, M. Abdel Azeem, S.A. Mohamed, A. El-Hossiany and E. El-Desouky, Corrosion Inhibition and Adsorption Behavior of Nerium Oleander Extract on Carbon Steel in Hydrochloric Acid Solution, Int. J. Electrochem. Sci., 2019, 14, 3932-3948. doi: 10.20964/2019.04.44

8. A.S. Fouda, S.A. Abd El-Maksoud, A. El-Hossiany and A. Ibrahim, Corrosion Protection of Stainless Steel 201 in Acidic Media using Novel Hydrazine Derivatives as Corrosion Inhibitors, Int. J. Electrochem. Sci., 2019, 14, 2187-2207. doi: $10.20964 / 2019.03 .15$

9. O.A. Hazazi and M. Abdallah, Prazole Compounds as Inhibitors for Corrosion of Aluminum in Hydrochloric acid, J. Electrochem. Sci., 2013, 8, 8138-8152.

10. A.S. Fouda, E.Z. Gmal and M. A. Khalifa, Evaluation of Some New Synthesized Surfactants Based on Maleic Acid as Inhibitors for Low Carbon Steel (LCS) Corrosion in 1.0 M HCl Solution, Z. Phys. Chem., 2020, 234, no. 2. doi: 10.1515/zpch-2018-1361

11. R. Vera, R. Schrebler, P. Cury, R. Del Rio and H. Romero, Corrosion protection of carbon steel and copper by polyaniline and poly(ortho-methoxyaniline) films in sodium chloride medium. Electrochemical and morphological study, J. Appl. Elecrochem., 2007, 37, 519-525. doi: 10.1007/s10800-006-9284-y 
12. B. Hafez, M. Mokhtari and H. Steli, Environmentally friendly inhibitor of the corrosion of mild steel: Commercial oil of Eucalyptus, Int. J. Corros. Scale Inhib., 2019, 8, no. 3, 573-585. doi: 10.17675/2305-6894-2019-8-3-8

13. A.S. Fouda, A. El-Hossiany and H. Ramadan, Calotropis Procera plant extract as green corrosion inhibitor for 304 stainless steel in hydrochloric acid solution, Zaštita Materijala, 2017, 58, no. 4, 541-555. doi: 10.5937/ZasMat1704541F

14. A. Popova, M. Christov, S. Raicheva and E. Sokolova, Adsorption and inhibitive properties of benzimidazole derivatives in acid mild steel, Corros. Sci., 2004, 46, 1333 1350. doi: $10.1016 /$ j.corsci.2003.09.025

15. A. Fouda, M. Eissa and A. El-Hossiany, Ciprofloxacin as Eco-Friendly Corrosion Inhibitor for Carbon Steel in Hydrochloric Acid Solution, Int. J. Electrochem. Sci., 2018, 13, 11096-11112. doi: 10.20964/2018.11.86

16. A.S. Fouda, H. Ibrahim, S. Rashwan, A. El-Hossiany and R.M. Ahmed, Expired Drug (pantoprazole sodium) as a Corrosion Inhibitor for High Carbon Steel in Hydrochloric Acid Solution, Int. J. Electrochem. Sci., 2018, 13, 6327-6346. doi: 10.20964/2018.07.33

17. I. Lukovits, K. Palfi, I. Bako and E. Kalman, LKP Model of the Inhibition Mechanism of Thiourea Compounds, Corrosion, 1997, 53, 915-919. doi: 10.5006/1.3290275

18. A.S. Fouda, A. Abdallah and M. Yousef, Corrosion Inhibition and Adsorption Properties of Cefixime on Carbon Steel in Acidic Medium, Chem. Sci. Rev. Lett., 2014, 3, 130143.

19. I. You, P. Zhao, Q. Liang and B. Hou, Berberine as a natural source inhibitor for mild steel in $1 \mathrm{M} \mathrm{H} \mathrm{H}_{2} \mathrm{SO}_{4}$, Appl. Surf. Sci., 2005, 252, 1245-1253. doi: 10.1016/j.apsusc.2005.02.094

20. S.K. Shukla and M.A. Quraishi, Cefalexin drug: A new and efficient corrosion inhibitor for mild steel in hydrochloric acid solution, Mater. Chem. Phys., 2010, 120, 142-147. doi: 10.1016/j.matchemphys.2009.10.037

21. M.M. Motawea, Corrosion Inhibition Efficiency of Expired Nitazoxanide Drug on Carbon Steel in Hydrochloric Acid Solution, Int. J. Electrochem. Sci., 2019, 14, 66826698. doi: $10.20964 / 2019.07 .25$

22. N.O. Eddy and E.E. Ebenso, Adsorption and Quantum Chemical Studies on Cloxacillin and Halides for the Corrosion of Mild Steel in Acidic Medium, Int. J. Electrochem. Sci., 2010, 5, 731-750.

23. M. Lebrini, F. Robert, P.A. Blandinières and C. Roos, Corrosion Inhibition by Isertia coccinea Plant Extract in Hydrochloric Acid Solution, Int. J. Electrochem. Sci., 2011, 6, 2443-2460.

24. V. Branzoi, F. Golgovici and F. Branzoi, Aluminium corrosion in hydrochloric acid solutions and the effect of some organic inhibitors, Mater. Chem. Phys., 2002, 78, no. 1, 122-131. doi: 10.1016/S0254-0584(02)00222-5

25. M.M. Saleh and A.A. Atia, Effects of structure of the ionic head of cationic surfactant on its inhibition of acid corrosion of mild steel, J. Appl. Electrochem., 2006, 36, 899905. doi: $10.1007 / \mathrm{s} 10800-006-9147-6$ 
26. X.H. Li, S.D. Deng and H. Fu, Synergism between red tetrazolium and uracil on the corrosion of cold rolled steel in $\mathrm{H}_{2} \mathrm{SO}_{4}$ solution, Corros. Sci., 2009, 51, 1344-1355. doi: 10.1016/j.corsci.2009.03.023

27. V.R. Saliyan and A.V. Adhikari, Inhibition of corrosion of mild steel in acid media by N'-benzylidene-3-(quinolin-4-ylthio)propanohydrazide, Bull. Mater. Sci., 2007, 31, 699-711. doi: 10.1007/s12034-008-0111-4

28. Z.H. Tao, S.T. Zhang, W.H. Li and B.R. Hou, Corrosion inhibition of mild steel in acidic solution by some oxo-triazole derivatives, Corros. Sci., 2009, 51, 2588-2595. doi: 10.1016/j.corsci.2009.06.042

29. M. El Achouri, S. Kertit, H.M. Gouttaya, B. Nciri, Y. Bensouda, L. Perez, M.R. Infante and $\mathrm{K}$. Elkacemi, Corrosion inhibition of iron in $1 \mathrm{M} \mathrm{HCl}$ by some gemini surfactants in the series of alkanediyl- $\alpha, \omega$-bis-(dimethyl tetradecyl ammonium bromide), Prog. Org. Coat., 2001, 43, 267-273. doi: 10.1016/S0300-9440(01)00208-9

30. S.F. Mertens, C. Xhoffer, B.C. De Cooman and E. Temmerman, Short-Term Deterioration of Polymer-Coated 55\% Al-Zn Part 1: Behavior of Thin Polymer Films, Corrosion, 1997, 53, 381-388. doi: 10.5006/1.3280481

31. A.S. Fouda, K. Shalabi and A. El-Hossiany, Moxifloxacin Antibiotic as Green corrosion Inhibitor for Carbon Steel in $1 \mathrm{M} \mathrm{HCl}, J$. Bio- Tribo- Corros., 2016, 2, 18. doi: 10.1007/s40735-016-0048-X

32. A.J. Trowsdate, B. Noble, S.J. Haris, I.S.R. Gibbins, G.E. Thomson and G.C. Wood, The influence of silicon carbide reinforcement on the pitting behaviour of aluminium, Corros. Sci., 1996, 38, 177-191. doi: 10.1016/0010-938X(96)00098-4

33. E. Kus and F. Mansfeld, An evaluation of the electrochemical frequency modulation (EFM) technique, Corros. Sci., 2006, 48, 965-979. doi: 10.1016/j.corsci.2005.02.023

34. R. Nagalakshmi, L. Nagarajan and S. Rajendran, Corrosion Resistance of SS3161 In Artificial Urine In Presence Of D-Glucose, Int. J. Nano Corros. Sci. Eng., 2014, 1, 39 49. 